\title{
EFFECT OF CORTICOTROPHIN ON HYPOTHALAMIC SYNDROME IN CHILDREN
}

BY

\author{
N. R. BUTLER, D. H. H. PULLON and A. H. SNAITH \\ From The Hospital for Sick Children, Great Ormond Street, London
}

(RECEIVED FOR PUBLICATION JULY 22, 1959)

Bauer (1954), in reviewing 60 cases of hypothalamic syndrome reported at all ages in the literature, named the principal signs in descending order of frequency as precocious puberty, hypogonadism, diabetes insipidus, psychic disturbances, somnolence, obesity, thermodysregulation, emaciation, convulsions, sphincter loss, bulimia, anorexia and dyshydrosis. Some of the above signs are clearly due to abnormal secretion by the pituitary gland, and those specifically resulting from a deficiency of adrenocorticotrophic hormone might be expected to respond to replacement therapy since the value of corticotrophin (or of cortisone) is well established in the prevention and treatment of hypopituitary coma (Caughey, 1958). The pituitary gland is under the control of the hypothalamus and it is not clear whether certain signs are due purely to hormone deficiency or to direct interference with the hypothalamic vegetative centres; this applies to disturbance of appetite and body weight, mental alertness and body temperature. Damage to hypothalamic centres by an astrocytoma causes emaciation and increased appetite in the syndrome described by Russell (Russell, 1957; Kagan, 1958); these symptoms do not respond to corticotrophin in spite of other evidence of depression of pituitary function. Damage to the vegetative centres probably also explains the failure to respond to corticotrophin or cortisone in some cases of collapse following operation in the hypothalamic region (Northfield, 1955).

We now report four cases of hypothalamic syndrome in whom a stuporose state responded well to treatment with corticotrophin, which suggests that the underlying cause might be anterior pituitary deficiency rather than damage to the vegetative centres. Anorexia and wasting, which accompanied the stuporose state in two of the cases, also responded to corticotrophin. A space-occupying lesion at the base of the brain was accompanied in all these cases by an endocrine disturbance, in three cases by diabetes insipidus and in one by precocious puberty.

The four cases came under the care of $\mathrm{Mr}$. Wylie McKissock at The Hospital for Sick Children, Great Ormond Street.

\section{Case Reports}

Case 1 (R.S.). At the age of $9 \frac{1}{2}$ years this boy had a convulsion with residual weakness of the left arm. Two and a half years later he developed diabetes insipidus. He was admitted to The Hospital for Sick Children, Great Ormond Street. After air studies had been carried out it was concluded that there were intracranial lesions in the right frontal and pineal regions. A large port-wine naevus over the right forehead indicated that cerebral angiomata were probably present. During the next year the patient became progressively listless. Papilloedema developed and a further ventriculogram carried out in Sweden confirmed multiple intracranial lesions (Professor Olivecrona). The basal metabolic rate was found to be minus 34 per cent. Thyroid extract effected an improvement. Eight months later he was readmitted to The Hospital for Sick Children, Great Ormond Street, having been doubly incontinent for a month. His fluid intake, previously high, was estimated to have gone down to approximately one litre daily and he was refusing food. He was found to be in a grossly wasted, stuporose and apathetic state. He was hypothermic (oral temperature $95^{\circ} \mathrm{F} .\left(35^{\circ} \mathrm{C}\right.$.)) and the blood pressure was $60 / 40 \mathrm{~mm}$. Hg. The urinary 17-ketosteroid excretion was $1.2 \mathrm{mg}$./24 hours and the 17-hydroxysteroids were $2.7 \mathrm{mg}$./24 hours. * The blood cholesterol was $98 \mathrm{mg}$. per $100 \mathrm{ml}$. A glucose tolerance test gave the following figures: fasting $82 \mathrm{mg}$., and then at 30-minute intervals after an initial $50 \mathrm{~g}$. of oral glucose, 91, 132, 176, 252 and $169 \mathrm{mg}$. per $100 \mathrm{ml}$. Plasma

* In our laboratory the normal range for 17-ketosteroids for children of 9 to 12 years is $1 \cdot 1-9.5 \mathrm{mg} . / 24$ hours, mean $3.8 \mathrm{mg} . / 24$ hours; and for 17-hydroxysteroids, 1.0-8.2 mg./24 hours; mean $3.8 \mathrm{mg}$. $/ 24$ hours. 
electrolyte values were all increased; the plasma sodium was $156 \mathrm{mEq} . / 1$., the plasma potassium $5.9 \mathrm{mEq} . / 1$. and the plasma urea $137 \mathrm{mg}$. per $100 \mathrm{ml}$.

Progress AFter Corticotrophin. Replacement therapy was started with corticotrophin $20 \mathrm{mg}$. b.d. The fluid intake was raised to $3 \frac{1}{2} 1$. daily to counteract hyperelectrolytaemia, but pitressin was not given at this stage. The calorie intake was kept at approximately 2,000 calories, using a fortified dried milk preparation with added vitamins (Complan). During the next two days the patient became more alert, his oral temperature rose to normal and the blood pressure increased to $130 / 70 \mathrm{~mm}$. Hg. There was a good eosinophil response to the first dose of corticotrophin with a fall from 238 to 128 per c.mm. in four hours and subsequently to 40 per c.mm. The urinary 17 -ketosteroids rose steadily to $9.3 \mathrm{mg} . / 24$ hours, and the 17-hydroxysteroids to $25 \cdot 4$ mg./24 hours. Corticotrophin was then cut down by stages to $5 \mathrm{mg}$. daily and on this dosage the patient's condition remained greatly improved. The output of urine was now 2-3 1. daily. The hyperelectrolytaemia remained unchanged. The fluid intake was therefore increased to 51 . daily and pitressin was started in a dosage of 1 unit daily. Four days later the patient rapidly became disorientated and then comatose. It was thought that this was probably due to overhydration. Intravenous saline was given, followed, as he improved, by sodium chloride orally and D.O.C.A. $5 \mathrm{mg}$. daily by injection. Subsequently he began to lose salt through the kidney, and sodium chloride by mouth and D.O.C.A. were relatively ineffective in maintaining the plasma sodium chloride level in equilibrium. It was thought that a cerebral salt-wasting syndrome had developed, though the possibility of salt loss induced by overhydration could not be excluded. Two months later a ventriculogram was done with a view to a subsequent brain biopsy. Two hours after ventriculography the patient became profoundly unconscious and there was an abrupt fall in the excretion of sodium. This collapse was presumably due to damage to the vegetative centres. He died in coma two weeks later.

At autopsy (Dr. Martin Bodian) the diagnosis of cerebral angiomata was confirmed. The hypothalamus was involved by an angioma but this was not invading the pituitary gland.

COMMENT. In this boy with a cerebral angioma involving the hypothalamus, improvement in alertness, weight and appetite showed that corticotrophin had been of benefit. Long-standing diabetes insipidus later became complicated by a salt-losing syndrome and further damage to the vegetative centres led to coma and death.

Case 2 (M.H.). This girl, aged $10 \frac{1}{2}$ years, had a year's history of lethargy, poor appetite and loss of weight, with headaches and vomiting for six months. The child was admitted to The Hospital for Sick Children, Great Ormond Street, where ventriculography showed a suprasellar space-occupying lesion largely blocking the third ventricle. She was transferred to the National Hospital for Nervous Diseases, Queen's Square, where an inoperable suprasellar tumour was found and was implanted with radioactive gold seeds. Post-operatively she developed a right hemiparesis. She became very drowsy and the blood pressure fell to $70 / 50 \mathrm{~mm}$. Hg. Next day her condition was still stuporose and the oral temperature was $94^{\circ} \mathrm{F}$. $\left(34 \cdot 4^{\circ} \mathrm{C}\right.$.). At this time the plasma sodium was $131 \mathrm{mEq} . / \mathrm{l}$., potassium $5 \cdot 1 \mathrm{mEq} . / 1$. and urea $75 \mathrm{mg} . / 100 \mathrm{ml}$. Urinary steroid levels were low; 17-ketosteroid excretion was $0.7 \mathrm{mg} . / 24$ hours and 17-hydroxysteroids were less than $1.0 \mathrm{mg}$./24 hours. The plasma cholesterol was $276 \mathrm{mg}$. per $100 \mathrm{ml}$.

Progress AfTer Corticotrophin. Therapy was commenced with $10 \mathrm{mg}$. b.d. of corticotrophin, subsequent to which the temperature rose progressively to $98^{\circ} \mathrm{F}$. $\left(36.7^{\circ} \mathrm{C}\right.$.) and she became much brighter. Right hemiparesis and dysphagia remained. A month after the operation marked thirst was first noticed and found to be due to diabetes insipidus. Pitressin was not given at this stage. Two weeks later corticotrophin was reduced to $10 \mathrm{mg}$. daily and she was sent away for one month's convalescence. On her return she was found to be obese (weight gain $5.9 \mathrm{~kg}$.) and was noticed to show excessive hunger and unpredictable changes of mood. The plasma electrolyte levels were within normal limits. The urinary 17 -ketosteroid excretion was $10 \cdot 8$ mg./24 hours. Corticotrophin was discontinued, but during the subsequent week the patient again developed anorexia, apathy and a tendency to sleep during the day. Corticotrophin was recommenced in a dosage of $10 \mathrm{mg}$. every other day with good effect. She went out of hospital well stabilized on this dose and also on pitressin snuff 30 units daily. After a further three months corticotrophin was gradually reduced and she was doing well on pitressin alone six months later.

COMMENT. In this case of hypothalamic syndrome due to suprasellar tumour, lethargy and hypothermia responded well to corticotrophin. The patient's requirements fell rapidly but attempts to withdraw the drug after three weeks were unsuccessful, though treatment was successfully discontinued three months later. Diabetes insipidus developed post-operatively. This was the only case in the series in which urinary steroid excretion was below normal before treatment.

Case 3 (P.H.). This girl, aged 10 years, had a history of excessive thirst and polyuria for three years. Deterioration of vision had been present for two years, culminating in complete blindness in the right eye one month before admission. Headaches, vomiting and somnolence were recent features. On admission to The Hospital for Sick Children she was drowsy but cooperative. The blood pressure was $95 / 60 \mathrm{~mm}$. $\mathrm{Hg}$. The urinary specific gravity never rose above 1.003 and a diagnosis of diabetes insipidus was made. Ventriculography showed a space-occupying lesion in the pituitaryhypothalamic region. Craniotomy revealed a dark red 
mass which appeared to be welling from the pituitary fossa. Removal was impossible. It had the appearance of a teratoma and this was confirmed histologically. After the operation she remained drowsy, waking only to be fed. Body temperature was normal. The plasma sodium was $134 \mathrm{mEq} . / 1$. and plasma potassium 4.4 $\mathrm{mEq} . / \mathrm{l}$. The urinary 17 -ketosteroids were $3.5 \mathrm{mg}$. $/ 24$ hours and the 17-hydroxysteroids $2.2 \mathrm{mg}$./24 hours.

Progress after Corticotrophin. Corticotrophin, 20 mg. b.d., was given in view of the drowsiness. Within 48 hours she became much more alert with an increased appetite and by the fourth day she wanted to get out of bed. The urinary 17 -ketosteroids rose to $17.9 \mathrm{mg} / 24$ hours and the 17 -hydroxysteroids to $41 \cdot 7 \mathrm{mg}$. $/ 24$ hours. Corticotrophin was gradually withdrawn after 10 days, and five days after the last dose she was transferred to another hospital for radiotherapy. The drowsiness returned rapidly but again responded promptly to corticotrophin, which was discontinued after three weeks, this time without any recurrence of symptoms. Nine months later she remained well.

Before craniotomy the average daily urinary output in this patient was $1 \cdot 41$, rising to $2 \cdot 21$. during the five days following operation; after five days on corticotrophin it reached $9 \cdot 7$ 1./24 hours, whereupon corticotrophin was withdrawn. No pitressin was being given at this time.

COMMENT. As in the previous case corticotrophin was principally of benefit post-operatively in improving the alertness of a patient with suprasellar tumour and diabetes insipidus. A relapse occurred during radiotherapy but a second course was needed for only three weeks and the patient was well apart from diabetes insipidus nine months later.

Case 4 (D.R.). The patient was a boy aged 9 years. At the age of 8 years pubic hair and enlargement of the penis were noticed. Six months later vomiting began. Five weeks before admission he had two major convulsions and thereafter developed headaches, anorexia, lassitude and a squint. On admission he answered questions readily, though he was otherwise lethargic and content to lie in bed all day. He was emaciated (weight $48 \mathrm{lb}$. $(21 \cdot 8 \mathrm{~kg}$.)) (Fig. 1). The penis and testes were of adult proportions. The temperature was normal and the blood pressure $140 / 90 \mathrm{~mm}$. $\mathrm{Hg}$. The plasma sodium was $132 \mathrm{mEq} . / 1$. and the plasma potassium $5.1 \mathrm{mEq}$./1. The urinary 17 -ketosteroids were $2.6 \mathrm{mg}$./ 24 hours and the 17-hydroxysteroids $5.9 \mathrm{mg} . / 24$ hours. A glucose tolerance test was normal with a fasting level of $97 \mathrm{mg}$. and at 30-min. intervals after $25 \mathrm{~g}$. of glucose 97, 156, $135,97,103$ and $97 \mathrm{mg}$. per $100 \mathrm{ml}$. Ventriculography showed space-occupying lesions in the left subfrontal and suprasellar regions; there was also internal hydrocephalus and the presence of a third lesion in the posterior fossa was suspected. Craniotomy was not undertaken because of multiple lesions. During the next two weeks the patient remained lethargic and his emaciation continued in spite of adequate fluid and calorie intake with 'complan' via a nasal catheter.

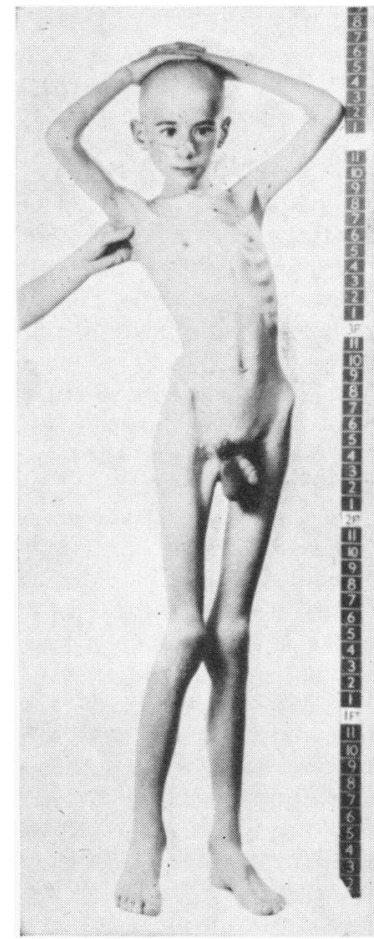

FIG. 1.-Case 4. On admission. Note gross emaciation and sexual precocity.

Progress after Corticotrophin. Corticotrophin 20 mg. daily was then given. Six days later he was less lethargic, gaining weight and feeding himself. The

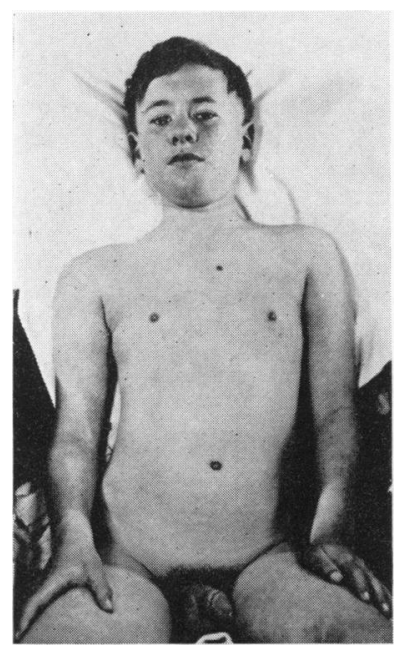

Fig. 2.-Case 4. Shows response of emaciation to corticotrophin. 
urinary 17 -ketosteroids were $6 \cdot 1 \mathrm{mg} . / 24$ hours and the 17-hydroxysteroids $6.2 \mathrm{mg} . / 24$ hours. His weight increased slowly to $61 \mathrm{lb}$. $(27 \cdot 7 \mathrm{~kg}$.) a month later. $\mathrm{He}$ was by then fully alert but not euphoric. He was transferred to another hospital for deep x-ray therapy after which corticotrophin was gradually withdrawn. Three months later his clinical condition remained good and he has continued to improve (Fig. 2).

Comment. Here, as in Case 1, lethargy and emaciation were associated with a suprasellar lesion as part of multiple inoperable intracranial lesions. A rapid response occurred to corticotrophin, which was later withdrawn successfully after radiotherapy. Isosexual precocity was also a feature.

\section{Discussion}

The fact that the administration of corticotrophin coincided with correction of stupor and improvement in the general condition of all four patients suggests that there was an initial depression of pituitary adrenocorticotrophin secretion for which corticotrophin acted as a replacement. However, laboratory investigations provided little confirmatory evidence of adrenocortical deficiency. Glucose tolerance tests in two of the patients did not show the typical change of hypoglycaemia over-responsiveness. Insulin tolerance tests were not performed. The eosinophil response after corticotrophin was measured in Case 1; this was normal, whereas in hypopituitarism a delayed or diminished depression of the eosinophils from secondary adrenocortical failure may occur, depending upon the duration of the pituitary failure (Nabarro, 1957). In our cases the plasma sodium and potassium levels did not show changes typical of adrenocortical failure. There was no delayed increase in steroid excretion after corticotrophin was administered. Two cases (1 and 3) showed a marked diuresis after the administration of corticotrophin, but this is not strictly evidence of initial depression of adrenocorticotrophic hormone secretion since a rise in solute excretion may occur consequent upon an increase in appetite. On a fixed dietary intake corticotrophin will not influence urinary volume in cases of anterior and posterior pituitary deficiency (Leaf, Manby, Rasmussen and Marasco, 1952). The overhydration which occurred in Case 1 was due to excess intake of water and pitressin and not to lack of corticosteroids since at that time corticotrophin had already been administered and steroid excretion was well within the normal range. The special investigations therefore showed no major deficiency in those aspects of the pituitary-adrenocortical mechanism which could be investigated.
Cases of post-operative coma due to tumours in and around the pituitary gland have previously been reported to respond to steroid replacement; in contrast to our cases, these usually showed evidence of long-standing pituitary deficiency and required permanent substitution therapy. In our three cases, who survived, corticotrophin was withdrawn successfully. If, as seems likely, there was no permanent or severe damage to the hypothalamic anterior pituitary system in our cases, the response to corticotrophin must be explained on a different basis. Two possibilities might account for the beneficial effect. First, the improvement may have been due to excessive secretion of corticosteroids which the corticotrophin stimulated. Corticosteroids improve the appetite and alertness in normal subjects. An alternative explanation is that there was a temporary depression of adrenocorticotrophic hormone, not shown in our tests, and that this was reversed by the general improvement which followed hormonal and surgical treatment. Full assessment of anterior pituitary activity was handicapped in two ways; first, by the ill state of the children which precluded full endocrine investigations, and second, by the fact that they had not reached the age of puberty; after puberty the recognition of hypopituitarism may be made more easy by such signs as hypogonadism, loss of pubic and axillary hair and low steroid excretion.

Whatever the explanation, the amelioration in the stupor and general condition of the four children was striking and it appears advisable to administer corticotrophin to children with lesions in the hypothalamic-pituitary region before surgery is undertaken. All our cases had an associated endocrine abnormality, such as diabetes insipidus or precocious puberty, though in one child the endocrine defect did not appear until post-operatively; this is in contrast to one case of suprasellar tumour we have seen recently in a boy of 9 , who showed no associated endocrine defect and in whom the wasting and stupor did not respond to corticotrophin.

\section{Summary}

The response to treatment with corticotrophin is described in four cases of hypothalamic syndrome, i.e. children with space-occupying lesions at the base of the brain associated with endocrine disturbances, stupor and wasting.

The difficulties of diagnosing anterior pituitary deficiency in the pre-pubertal child are discussed and it is suggested that all children with lesions in the region of the hypothalamus and pituitary gland should be given corticotrophin (or cortisone) before surgical intervention. 
We should like to thank Mr. Wylie McKissock for permission to study these cases, Professor A. A. Moncieff and Dr. W. W. Payne for their advice, and the Research Committee of the hospital for its support.

\section{REFERENCES}

Bauer, H. G. (1954). Endocrine and other clinical manifestations of hypothalamic disease; survey of 60 cases with autopsies. J. clin. Endrocr., 14, 13.

Caughey, J. E. (1958). In Modern Trends in Endocrinology, p. 132. Edited by $\mathbf{H}$. Gardiner-Hill. Butterworth, London.
Harris, G. W. (1955). Neural Control of the Pituitary Gland. Edward Arnold, London.

Kagan, H. (1958). Anorexia and severe inanition associated with a tumour involving the hypothalamus. Arch. Dis. Childh., 33, 257.

Leaf, A., Mamby, A. R., Rasmussen, H. and Marasco, J. P. (1952). Some hormonal aspects of water excretion in man. J. clin. Invest., 31, 914.

Nabarro, J. D. N. (1957). The diagnosis of adrenal critical dysfunction. Brit. med.J., 2, 1018.

Northfield, D. W. C. (1955). Discussion on pituitary syndromes. Proc. roy. Soc. Med., 48, 879 .
Motheld

Russell, A. (1957). A diencephalic syndrome of hyperkinetic emaciation typically linked to predominant elation in infancy and early childhood. Excerpta med. (Amst.), Sect. VIII, 10, Congress Issue, p. 111. 6th International Congress of Neurology, Brussels. 